\title{
Research on the Tourists' Type and Behavior based on the Fog and Haze Perception: Taking Xi'an as a Case
}

\author{
Yang Jun-hui* \\ School of Tourism, Xi'an International Studies University, Xi'an, China
}

\begin{abstract}
Under the background of tourism affected by the fog and haze, this study takes Xi'an as a case , focuses on the tourists' type and behavior, and forms the following conclusions. The tourist can be divided into blunt type, normal type and sensitive type based on the perception to the fog and haze. The blunt type has demographics of male, elderly people, lower educated, low income, and from the North of China. The sensitive type has demographics of female, single, middle-aged, higher educated, and from the South of China. The blunt and sensitive types who pay less attention to the fog and haze in the before travel stage, have a rational willingness behavior, and have a significant increase on the attention rate to future decision after this travel. But the sensitive type prefers to the quality and healthy behavior in the stage of during tour.
\end{abstract}

\section{Introduction}

The fog and haze is a phenomenon of complicated and disastrous weather, which refers to the atmosphere pollution of all kinds of suspended particles in the air. The fog and haze has a great influence on the air quality, tourism landscape, tourism experience, tourist satisfaction, tourist health, tourism traffic and so on, which will further harm to tourism economy and tourism image. So it is necessary to focus on the impact of fog and haze on tourism development.

According to literature review, we found that the former research focuses on the fog and haze's influence to tourism economy and tourists' perception to the fog and haze. On the aspect of the fog and haze's influence to tourism economy, Sajjad ${ }^{[1]}$ and Tang ${ }^{[2]}$ believed that the fog and haze weather had a significant negative impact on regional tourism. Anaman ${ }^{[3]}$ found that the fog and haze had caused the direct economic loss about 8 million dollars to Brunei in 1997 to 1998. Yan's research shows that the spatial distribution of the inbound tourists' loss and the degree of the fog and haze's pollution in 31

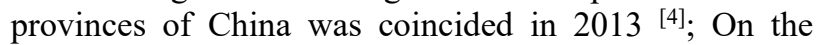
aspect of tourists' perception to the fog and haze, Zhang's study had found that the tourists' risk perception to the fog and haze was shown as "body's risk $>$ function's risk $>$ psychological risk $>$ cost's risk" ${ }^{[5]} . \mathrm{Li}^{[6]}$ believed that the fog and haze's perception of foreign tourists was lower than these of Chinese tourists. Zhang ${ }^{[7]}$ and Cheng ${ }^{[8]}$ believed that the fog and haze weather had a negative impact on tourists' decisions; On the other aspects, Zhou ${ }^{[9]}$ thought that the fog and haze weather not only impacted on the tourism activities, but also changed the tourism theory. Zou ${ }^{[10]}$ believed that the fog and haze weather in China's major tourism cities had a characteristics of seasonal and spatial distribution.

It can be found from the literature review that the scholars have made a great deal on the research of the fog and haze's influence to tourism and tourist, and laid a theoretical foundation for the later related research. However, few scholars have paid attention to the tourist classification based on the fog and haze perception, and studied the response of tourist from the stages of before, during and after the tour in the fog and haze weather. In order to enrich the research of the fog and haze's influence to tourism and guide the tourism practice development, this study takes Xi'an as a case, classifies the tourists and systematically analyses the behavior characteristic of tourist based on the fog and haze perception from the stages of before, during and after the tour

\section{Case and Data}

\subsection{Case Introduction}

This study takes Xi'an as a case. Xi'an is a world famous historical and cultural city, the first excellent tourism cities and the best tourism destination in China. It is also a destination that must be visited by most domestic and foreign tourists. In 2016, Xi'an has received 150 million tourists from home and abroad, and achieved the tourism income of 121.3 billion Yuan ${ }^{[11]}$. But in recently years, owing to the extensive development of $\mathrm{Xi}^{\prime}$ an and surrounding areas and the energy-resource structure of heat-supply in winter, the fog and haze weather has

\footnotetext{
*Corresponding author: yjh7821@163.com
} 
frequently appeared in Xi'an in winter. According to the monitoring data from Xi'an Environmental Protection Bureau, the fog and haze weather in Xi'an was 65 days from January 1 to March 19 in $2016^{[12]}$. The frequently occurred fog and haze weather has a great impact on the tourism industry in Xi'an, which further aggravates the seasonality of Xi'an tourism. Therefore, Xi'an is a typical and representative place to explore the scientific issues of tourists' perception types and behavior Characteristic.

\subsection{Data Acquisition}

The data includes two aspects. One data is tourists' information, which includes the tourists' demographic characteristics, and tourism behavior in Xi'an under the fog and haze weather from the before, during and after tourism stages. Another data is the air quality information of tourists' origin place in November and December 2016, which acquired through the China air quality online monitoring and analysis platform (https://www.aqistudy.cn).

The survey was implemented in many famous scenic spots of Xi'an, such as the Shaanxi History Museum, the Dayan Pagoda, and the Xi'an Ancient City Wall from December 26, 2016 to January 6, 2017. During the 12 days of the survey, the moderate and severe fog and haze weather is 9 days (Table 1), and the Primary and secondary school have closed for two times. The Air Quality Index (AQI) of Xi' an was up to 483 in January 5, 2017, it is the most serious day of the fog and haze weather in the history. The tourists in Xi' an had a deep understanding of the fog and haze's influence on their behavior and experience, so the survey results can effectively reflect the tourists' perception to the fog and haze weather. A total of 240 questionnaires were collected and 225 questionnaires were valid, the effective rate is $93.75 \%$.

Table 1. The Air Quality Data of Xi'an during Investigation Period

\begin{tabular}{|c|c|c|c|c|c|c|c|c|c|c|c|c|}
\hline Month & \multicolumn{5}{|c|}{ December 2016 } & \multicolumn{6}{|c|}{ January 2017 } \\
\hline Day & $\mathbf{2 6}$ & $\mathbf{2 7}$ & $\mathbf{2 8}$ & $\mathbf{2 9}$ & $\mathbf{3 0}$ & $\mathbf{3 1}$ & $\mathbf{1}$ & $\mathbf{2}$ & $\mathbf{3}$ & $\mathbf{4}$ & $\mathbf{5}$ & $\mathbf{6}$ \\
\hline $\begin{array}{c}\text { Air Quality } \\
\text { Degree }\end{array}$ & G & G & G & M & S & S & S & S & S & S & S & S \\
\hline AQI & 73 & 76 & 97 & 165 & 256 & 350 & 393 & 341 & 408 & 473 & 483 & 209 \\
\hline $\begin{array}{c}\text { PM2.5 } \\
\left(\mu \mathrm{g} / \mathrm{m}^{3}\right)\end{array}$ & 37 & 46 & 71 & 125 & 205 & 299 & 346 & 290 & 366 & 467 & 490 & 170 \\
\hline $\begin{array}{c}\text { PM10 } \\
\left(\mu \mathrm{g} / \mathrm{m}^{3}\right)\end{array}$ & 93 & 95 & 121 & 176 & 272 & 375 & 410 & 365 & 441 & 556 & 591 & 236 \\
\hline
\end{tabular}

Note: the "G" refers to "good", "M" refers to "moderate", "S" refers to "serious"

Data Sources:

http://www.tianqihoubao.com/aqi/xian-201612.html; http://www.tianqihoubao.com/aqi/xian-201701.html

\section{Tourists' Classification Based on the Fog and Haze Perception}

\subsection{Tourists Type of Perception to the Fog and Haze}

The theme of "tourists' cognition to the fog and haze weather in hometown" in the questionnaire has three options, that is often, occasional and no fog and haze weather. Comparing the tourists' cognition with actual Air Quality in tourists' hometown, the tourists can be divided into five types, such as strong sensitive type, weak sensitive type, normal type, weak blunt type and strong blunt type (Table 2). But limited by the quantity of questionnaire, this study combines "strong sensitive type" and "weak sensitive type" as "sensitive type", "strong blunt type" and "weak blunt type" as "blunt type ", and finally forms the sensitive type, the normal type and the blunt type of tourists' perception to the fog and haze. The data of the demographics of three type tourists are showed in Table 3 and 4.

Table 2. Classification of Tourists' Perception to the Fog and Haze

\begin{tabular}{|c|c|c|c|}
\hline $\begin{array}{c}\text { Tourists } \\
\text { Cognition } \\
\text { Dir Quality } \\
\text { Degree }\end{array}$ & Often & Occasional & No \\
\hline Good & strong sensitive type & $\begin{array}{c}\text { weak sensitive } \\
\text { type }\end{array}$ & normal type \\
\hline Minuent & weak sensitive type & normal type & $\begin{array}{c}\text { weak blunt } \\
\text { type }\end{array}$ \\
\hline $\begin{array}{c}\text { Moderate and } \\
\text { severe }\end{array}$ & normal type & weak blunt type & $\begin{array}{c}\text { strong blunt } \\
\text { type }\end{array}$ \\
\hline
\end{tabular}

Table 3. Statistics of the Demographics of Tourists (Unit: \%)

\begin{tabular}{|c|c|c|c|c|}
\hline Demographics & Index & $\begin{array}{c}\text { blunt } \\
\text { type }\end{array}$ & $\begin{array}{c}\text { normal } \\
\text { type }\end{array}$ & $\begin{array}{c}\text { sensitive } \\
\text { type }\end{array}$ \\
\hline \multirow{2}{*}{ Gender } & Male & 36.07 & 30.33 & 33.60 \\
\hline & Female & 22.33 & 41.75 & 35.92 \\
\hline \multirow{2}{*}{ Marriage } & Single & 25.23 & 38.32 & 36.45 \\
\hline & Married & 33.90 & 33.05 & 33.05 \\
\hline \multirow{5}{*}{ Age } & $<18$ & 26.67 & 46.66 & 26.67 \\
\hline & $18-25$ & 26.03 & 34.24 & 39.73 \\
\hline & $26-45$ & 35.07 & 36.36 & 28.57 \\
\hline & $46-60$ & 17.65 & 32.35 & 50 \\
\hline & $>60$ & 42.31 & 34.62 & 23.07 \\
\hline \multirow{4}{*}{ Education } & Junior & 36.37 & 42.42 & 21.21 \\
\hline & Senior & 31.08 & 33.78 & 35.14 \\
\hline & College & 27.71 & 37.35 & 34.94 \\
\hline & Graduate & 25.71 & 28.57 & 45.72 \\
\hline \multirow{4}{*}{ Income } & $<1500$ & 38.18 & 29.09 & 32.73 \\
\hline & $1501-4500$ & 22.45 & 39.80 & 37.75 \\
\hline & $4501-7500$ & 36.36 & 30.91 & 32.73 \\
\hline & $>7500$ & 23.53 & 47.06 & 29.41 \\
\hline \multicolumn{2}{|c|}{ Total } & 29.78 & 35.55 & 34.67 \\
\hline
\end{tabular}

Table 4. Statistics of the Tourists' Origination

\begin{tabular}{|l|l|}
\hline Types & \multicolumn{1}{|c|}{ Province (number) } \\
\hline \multirow{3}{*}{ Blunt type } & $\begin{array}{l}\text { Gansu(4) Henan(8) Heilongjiang(2) Neimenggu(4) Ningxia(4) } \\
\text { Qinghai(2) Shandong(6) Shanxi(2) Shanxi(28) Sichuan(2) } \\
\text { Xinjiang(4) }\end{array}$ \\
\hline
\end{tabular}




\begin{tabular}{|c|c|}
\hline $\begin{array}{l}\text { Normal } \\
\text { type }\end{array}$ & 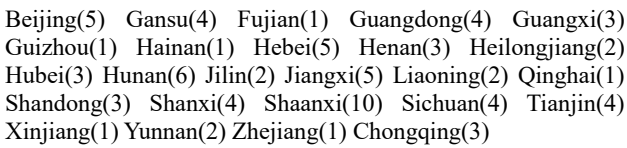 \\
\hline $\begin{array}{l}\text { Sensitive } \\
\text { type }\end{array}$ & 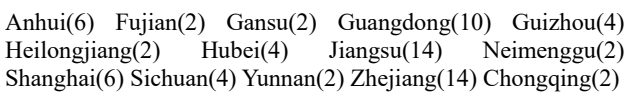 \\
\hline
\end{tabular}

\subsection{Demographic Characteristics of Each Tourists Types}

The results of survey, table 3 and 4 , showed that the tourists of normal type are the largest group (35.56\%), the percent of sensitive type is $35.56 \%$ which be less than the normal type, and the blunt type is the least group (29.78\%). From the perspective of gender, the percentage of male tourists' perception to the fog and haze is presented as "the blunt type $>$ the sensitive type $>$ the normal type", while the percentage of female is "the normal type $>$ the sensitive type $>$ the blunt type". That is to say, the male tourists' perception to the fog and haze is blunter than the female's. Marriage perspective, the percent of single tourists' perception to the fog and haze is showed as "the normal type $>$ the sensitive type $>$ the blunt type", while the percent of the married is "the blunt type $>$ the normal type = the sensitive type" and the number of each type is small. That's to say, the single tourists' perception to the fog and haze is correct or little sensitive, while the married has no significant difference in the fog and haze perception. Age perspective, the percent of the normal type is higher than other type among the tourists of less than 18 years old, the sensitive type has the more people than other type among the tourists of 18-25 and 46-60 years old, and the most elderly tourists belong to the blunt type. That's to say, the young and middle-aged tourists are more sensitive to the fog and haze weather while the elderly tourists are blunter. Education perspective, the proportion of the blunt type is declining with the promotion of education, while the sensitive type is on the rise. That is, the tourists with less knowledge are blunter to the fog and haze than the highly educated. Income perspective, the tourists with less than 1500 Yuan per month are blunt to the fog and haze, and the high income tourists' perception to the fog and haze is normal. Hometown perspective, most of the blunt type tourists are from the North China (97.01\%), and the sensitive type tourists mainly come from the Southern China (92.31\%), but the normal type tourists' home place is decentralization.

The following conclusions can be drawn from the above analysis. The blunt type has the demographic characteristics of male, elderly people, lower educated, low income, and from the North of China. The sensitive type has the demographic characteristics of female, single, middle-aged, higher educated, and from the South of China. The normal type has the demographic characteristics of female, single, juveniles, and higher income.

\section{Behavior Characteristics of the Blunt}

\section{and Sensitive Type}

Because there is sharp contrast of demographics between the blunt and sensitive type, the research chooses the blunt and sensitive type tourists to explore the tourism behavior from the stages of before, during, after the tour by comparison. There are two indexes of behavior in the stage of before tour, such as tourists' attention rate and knowing rate to the fog and haze. The willingness and actual behavior are the aspects of the tourists in the stage of during tour. Under the fog and haze weather, the tourists' willingness behavior may be represented as staying in the door, adjusting spot, shorten time, ending or leaving, the tourists' actual behavior may be showed as no change the schedules, adjusting spot, shorten time, and without staying indoors or leaving the city for the reason of field investigation. The tourists' response to the fog and haze in the after tour stage includes two aspects: attention rate and willingness behavior in the next tourism decisions. The statistical results of tourists' behavior are shown in Table 5.

Table 5. Statistics of Tourist Behavior from the Perception to Fog and Haze (Unit: \%)

\begin{tabular}{|c|c|c|c|c|}
\hline Stage & & Index & $\begin{array}{c}\text { Blunt } \\
\text { type }\end{array}$ & $\begin{array}{c}\text { Sensitive } \\
\text { type }\end{array}$ \\
\hline \multirow{2}{*}{$\begin{array}{l}\text { Before } \\
\text { the tour }\end{array}$} & \multicolumn{2}{|l|}{ Attention rate } & 55.22 & 55.13 \\
\hline & \multicolumn{2}{|c|}{ Knowing rate } & 49.25 & 43.59 \\
\hline \multirow{7}{*}{$\begin{array}{l}\text { During } \\
\text { the tour }\end{array}$} & \multirow{4}{*}{$\begin{array}{l}\text { Willingness } \\
\text { behavior }\end{array}$} & staying indoor & 29.9 & 28.21 \\
\hline & & adjusting spot & 28.36 & 21.79 \\
\hline & & \begin{tabular}{|l|} 
shorten time \\
\end{tabular} & 25.37 & 28.21 \\
\hline & & ending or leaving & 25.37 & 21.79 \\
\hline & \multirow{3}{*}{$\begin{array}{l}\text { Actual } \\
\text { behavior }\end{array}$} & no change & 41.79 & 35.9 \\
\hline & & adjusting spot & 37.31 & 42.31 \\
\hline & & shorten time & 20.9 & 21.79 \\
\hline \multirow{4}{*}{$\begin{array}{l}\text { After the } \\
\text { tour }\end{array}$} & \multicolumn{2}{|c|}{ Attention rate } & 73.13 & 79.49 \\
\hline & \multirow{3}{*}{\begin{tabular}{|l|}
$\begin{array}{l}\text { Willingness } \\
\text { behavior }\end{array}$ \\
\end{tabular}} & adjusting spot & 41.79 & 32.05 \\
\hline & & shorten time & 20.9 & 44.87 \\
\hline & & Measures & 37.31 & 23.08 \\
\hline
\end{tabular}

Shown from the statistics of tourists' behavior in the before tour stage, the attention rate of the blunt type is $55.22 \%$, and the knowing rate is $49.25 \%$. The attention rate of the sensitive type is $55.13 \%$, and the knowing rate is $43.59 \%$. The attention rate and knowing rate between the blunt and sensitive type are small, and have no significant difference. It shows that the tourists pay less attention to the fog and haze weather before travel, and even if the tourists knowing that the fog and haze weather will occur in the next days, they still choose to travel. Analysis of the reasons, although the blunt and sensitive type have a deviation perception to the fog and haze, tourists of the two types have no tourism experience under the fog and haze weather, they don't know that the fog and haze will affect their tourism activities and experience, harm to their physical and mental health. Thus the blunt and sensitive types likely ignore the factor of the fog and haze when they made the tourism decision.

Shown from the statistics of tourists' behavior in the during tour stage, under the fog and haze weather, the willingness behavior of the blunt type is represented as "staying indoor $>$ adjusting spot $>$ shorten time $=$ ending 
or leaving", and the actual behavior is presented as "no change $>$ adjusting spot $>$ shorten time". While the willingness behavior of the sensitive type is represented as "staying indoor $=$ shorten time $>$ adjusting spot $=$ ending or leaving", and the actual behavior is presented as "adjusting spot $>$ no change $>$ shorten time". From the comparison of the willingness behavior, it can be seen that the blunt and sensitive types have a strong and close willingness of "staying indoor", and the other willingness with high value of each types are different but positive action. So the blunt and sensitive types' willingness are rational and no different. From the comparison of the actual behavior, it can be seen that the blunt type has more behavior of "no change", and the sensitive type has high percentage of "adjusting spot". That's to say, the sensitive type has a higher perception to the fog and haze than the blunt one, and prefers to the positive behavior, such as "adjusting spot", no "staying indoor" or "ending/leaving". Analysis of the reasons, when facing the fog and haze weather, the blunt and sensitive type can make a rational analysis and judgment out of the experience quality and health needs. But influenced by the tourism opportunity, cost, time, and so on, the tourists will use the best way of self recognition to continue to travel.

Shown from the statistics of tourists' behavior in the after tour stage, for their own experience of the fog and haze, the blunt and sensitive types' attention rate have a significant increase in the next tourism decision, and the attention rate of the sensitive type is up to $24.36 \%$. When it meets the fog and haze weather in future travel, the blunt type's willingness will be present as "adjusting spot $>$ anti haze measures $>$ shorten time", and the sensitive type's willingness is as "shorten time $>$ adjusting spot $>$ anti haze measures". There is a big difference between the two groups. Analysis of the reasons, the blunt and sensitive types had a profound perception to the fog and haze in this travel, that the fog and haze will serious harm to experience and health. So they will be more concerned about the fog and haze weather in tourism destination. Because the sensitive type has a higher requirement for the environment than the blunt type, and the sensitive type regards that the behavior of "adjusting spot" can't deduce the influence of the widely fog and haze. Therefore, the sensitive type turns to the behavior of "shorten time".

\section{Conclusions}

Taking Xi'an as a case, this study focuses on the tourists' type and behavior based on the fog and haze perception, and draws the following conclusions.

(1) Tourists can be divided into three types: blunt type, normal type and sensitive type. Comparison to the tourists' perception to the fog and haze of hometown and the actual air quality, the tourists are divided into the blunt type, normal type and sensitive type. The blunt type has the demographics of male, elderly people, lower educated, low income, and from the North of China. The sensitive type has the demographic characteristics of female, single, middle-aged, higher educated, and from the South of China. The normal type has the demographic characteristics of female, single, juveniles, and higher income.

(2) Under the fog and haze weather, there are similarities and differences between the blunt and sensitive types. Tourists of blunt and sensitive type pay less attention to the fog and haze in the stage of before travel, and have a low attention and knowing rate in the process of tourism decision. The willingness behavior of blunt and sensitive types is rational, but there is a large difference between the blunt and sensitive types' actual behavior in the stage of during tour. The attention rate to next tourism decision has a significant increase between the blunt and sensitive types in the stage of after travel.

Influenced by subjective emotion, the tourists' evaluation of the fog and haze in hometown may not be completely correct, which will not reflect the deviation between the perception and fact correctly, and affect the accuracy of type division. The future research will increase the quantity of samples to avoid this problem.

\section{Acknowledgement}

This research was financially supported by Project of Shaanxi Education Department (No. 17JK0628) and Xi'an International Studies University (No. 17XWA04)

\section{Reference}

1. Sajjad F, Noreen U, Zaman K. Climate change and air pollution jointly creating nightmare for tourism industry $[\mathrm{J}]$. Environmental Science and Pollution research, 2014, 21(21): 12403- 12418.

2. Tang C C, Ma L, Song C Y. Do fog and haze affect Beijing inbound tourism?--An empirical study based on Panel data $[\mathrm{J}]$. Journal of Arid Land Resources and Environment, 2017,31 (1): 192-197.

3. Anaman K A, Chee N L. Economic impact of haze-related air pollution on the tourism industry in Brunei Darussalam [J]. Economic Analysis and Policy, 2000, 30(2):133-143.

4. Yan Y B, Zhang J. Impact of Smog Weather on the Amount of Inbound Tourists of China Based on the Natural Trend Curve [J]. Economic Geography, 2016, 36 (12): 183-188.

5. Zhang A P, Yu H. Risk perception and risk reduction of domestic tourists impacted by haze pollution in Beijing[J]. Resources Science, 2017,39(6):1148-1159.

6. Li J, Philip L. P, Wu B H, et al. The Impact of Smog on Risk Perception and Satisfaction of International and Domestic Tourists in Beijing [J]. Tourism Tribune, 2015,30 (10): 48-59.

7. Zhang A P, Zhong L S, Xu Y, et al. Tourists' perception of haze pollution and the potential impacts on travel: Reshaping the features of tourism seasonality in Beijing, China [J]. Sustainability, 2015, 7(3):2397-2414.

8. Cheng Li, Zhang T H, Fu Yang. Urban Residents' Cognition of Haze-fog Weather and Its Impact on 
Their Urban Tourism Destination Choice[J]. Tourism Tribune, 2015, 30 (10): 37-47.

9. Zhou M J, Wang Y P, Huan Z D. Haze pollution changes the basic tourism theory [J]. Tourism Forum, 2014,7 (7): 12-16.

10. Zou J H, Xu F X, Zou B, et al. Spatial-temporal Characteristics of Haze in the Key Tourism Cities of China[J].Tropical Geography,2018,38(1):143-150.

11. Shaanxi Statistical Bureau. Reporter of tourism statistics and monitoring of Xi' an in 2016 [EB/OL]. http://www. shaanxitj.gov.cn/site/1/html/126/131/ 139/16623.htm, 2017-10-17.

12. San Qin Net. The fine days of Xi'an in 2016 were only 33 days [EB/OL]. http://shanxi.news.163.com/ 16/0321/10/BIM63VN003 911B9M. Html, 2016-03-21. 